\title{
Smartphones are child's play, but what about the child labour?
}

Written by: Roel Nieuwenkamp, Chair of the OECD Working Party on Responsible Business Conduct

Last update: 24 January 2020

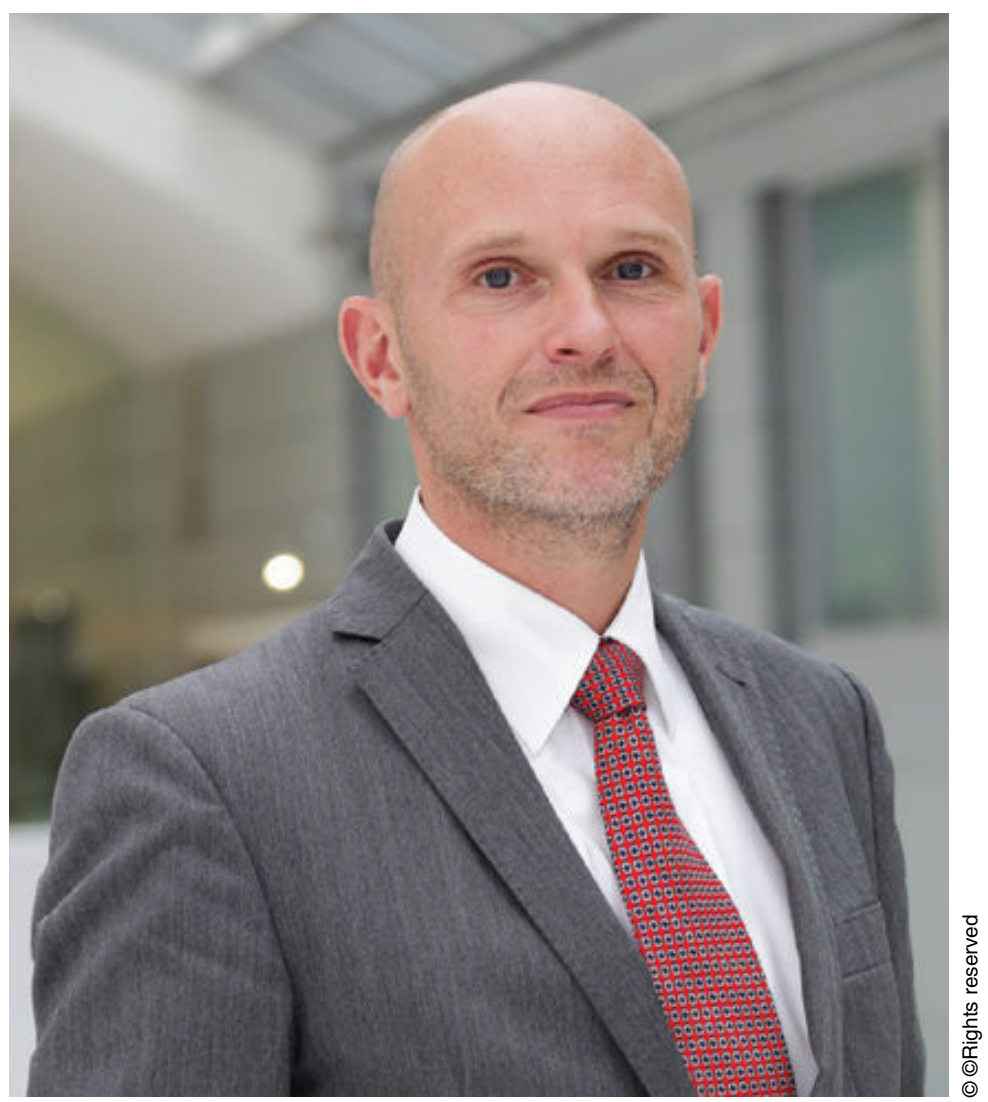

Digital technology depends on energy, and that energy depends on minerals. Take cobalt, for instance. Use of this ferromagnetic metal can be traced back to Ancient Egypt when it was used to taint ceramics. Today cobalt is an integral part of rechargeable lithium-ion batteries that go into smartphones, laptops and electric vehicles. The market for rechargeable lithium-ion batteries is expected to more than double to USD $\$ 77$ billion by 2024. Hence, for the "fourth industrial revolution" to succeed and to meet our important climate goals, we need cobalt-but at what cost? 
Recent press reports decry children, sometimes as young as five years old, working in cobalt mining under terrible conditions in the Democratic Republic of the Congo (DRC). These mines operate outside legal frameworks, without formal social, health or worker protection.

If your company operates in this sector, whether making or using cobaltdependent batteries, or the digital products they go into, and no matter where that cobalt enters in your supply chains, you cannot afford to take these press reports lightly. So, what can you do? The DRC produces more than $60 \%$ of the world's cobalt. Of this, most comes from large scale industrial mines, but around $30 \%$ comes from illegal mines where there is a marked risk of child labour being used. Given the DRC's huge market share, it is likely that some of its cobalt is present in your supply chain. But how can you be sure?

It is not easy. True, the OECD Guidelines for Multinational Enterprises call on companies to scrutinise their supply chains for human rights, labour, environmental and corruption impacts, but these supply chains are incredibly complex and long. How to know where the cobalt comes from? After all, the buyer of the Congolese cobalt affected by child labour, may in this case be a Chinese cobalt smelter, which would be several links up the supply chain and completely unknown to your firm: a sub-sub-sub-sub-supplier, if you like.

To be fair, the OECD's due diligence standard acknowledges that companies on the end of long supply chains cannot realistically know the mine of origin for all the metals in their product, but they should at least try to identify the smelters. But even if you manage to identify this smelter, what can you do to reduce your risk?

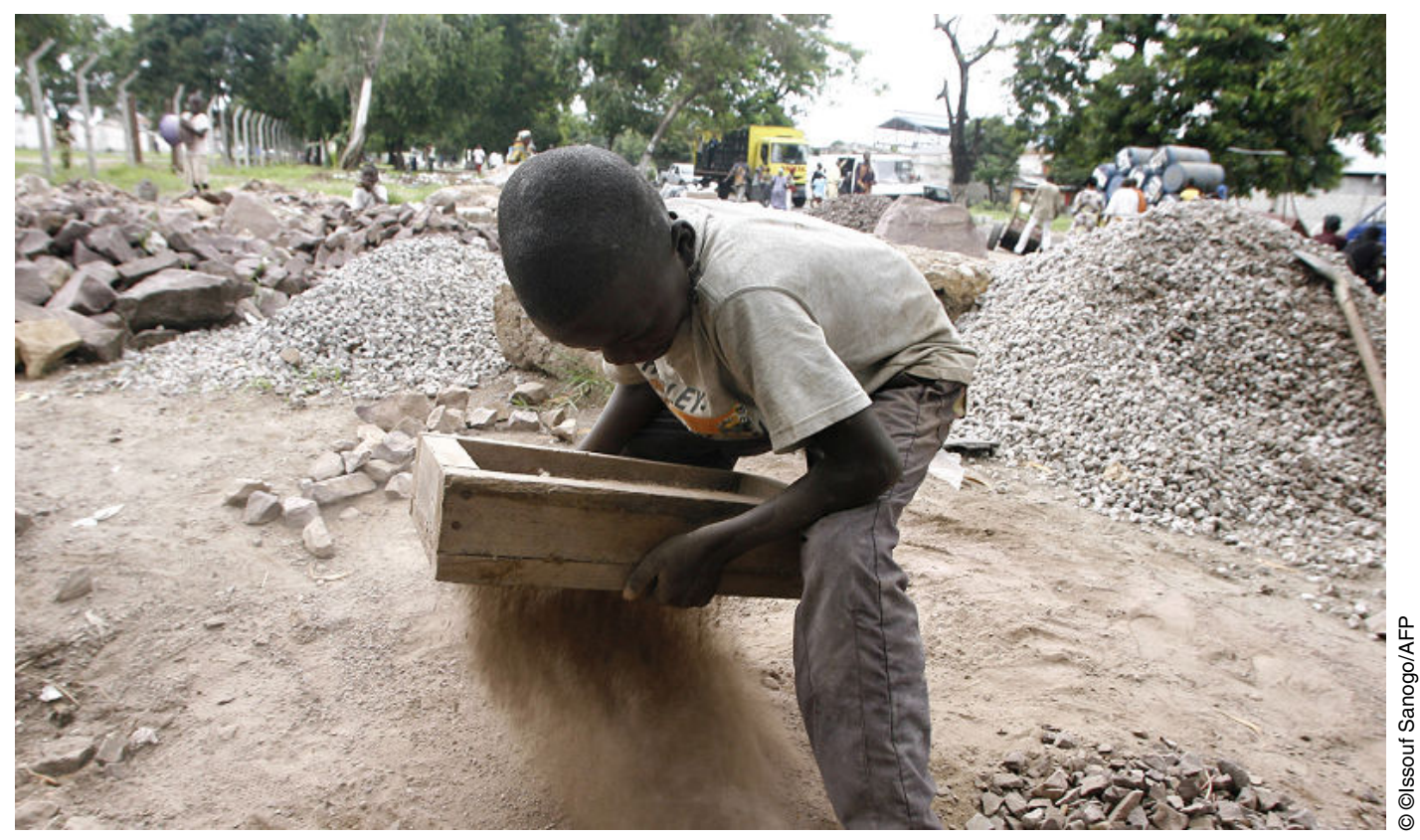


There are several avenues to consider. You could join an industry association that, collectively, as the largest buyers of lithium batteries, has leverage over the cobalt smelters, pushing them to use international standards to source cobalt responsibly and prevent child labour; an example is the Responsible Cobalt Initiative. The industry association may reach out to government officials in China, for instance, to get their support in aligning the cobalt smelters with responsible international standards.

However, the main responsibility for due diligence regarding supply chains rests with your fi $\mathrm{rm}$. The OECD can help, with a set of practical actions due to be published in 2017, which will explain in simple terms how to tackle the risks of the worst forms of child labour in the minerals supply chain.

Not all informality is bad per se. Roughly a fifth of the DRC's population relies on this type of mining, despite the terrible conditions. So walking away from the DRC is not the answer either, even if it were feasible given the DRC's share of production and the limited control you can hope to have over upstream suppliers. Clearly, the aim of any upstanding digital fi rm, both for moral and business reasons, is to work towards the prevention of child labour. Achieving this requires a collective effort to formalise and legalise the informal mining sector, remove children from the mines, and develop schools instead. This requires a herculean effort, and while companies can show intolerance to child labour and encouragement to tackle it, they cannot achieve change without working closely with the DRC government, local civil society and communities, as well as donors, to address the root causes of child labour. Only then can the cobalt supply chains be cleaned up for good.

Meanwhile, international organisations like ours can help put in place the conditions for progress. For instance, the China-OECD joint programme of work includes co-operation on responsible mineral supply chains. Indeed, the OECD has helped the China Chamber of Commerce of Metals Minerals and Chemicals Importers and Exporters (CCCMC), a Chinese industry association, set up the Responsible Cobalt Initiative. This includes international technology companies, battery manufacturers and Chinese smelters, working alongside the new Interministerial Commission on Child Labour of the Congolese government, using the OECD Due Diligence Standards for Responsible Mineral Supply Chains.

It shows how crucial engagement with governments and players across the spectrum can be to prevent risks, improve welfare and protect integrity and human rights.

The digital revolution is so promising in many ways, and is a harbinger of a cleaner world. The onus is on us all to work ever harder together to ensure what goes into our technology respects the highest standards. Our technology will be even smarter, and fairer, as a result. 
COECD Yearbook 2017

\section{References}

By the same author: "Corporate leaders: Your supply chain is your responsibility", in OECD Observer No 299, Q2 2014 http://oecdobserver.org/ news/fullstory.php/aid/4366/

Corporate_leaders:_Your_supply_chain_is_your_responsibility.html

Frankel, Todd (2016), "The Cobalt Pipeline: Tracing the path from deadly handdug mines in Congo to consumers' phones and laptops", in The Washington Post, 30 September https://www.washingtonpost.com/graphics/business/ batteries/congo-cobalt-mining-for-lithium-ion-battery/?tid=sm_tw

Responsible Algorithms in Business: Robots, fake news, spyware, self-driving cars and corporate responsibility http://oecdinsights.org/2017/01/13/ responsible-algorithms-in-business/

Practical actions for companies to identify and address the worst forms of child labour in the minerals supply chain https://mneguidelines.oecd.org/childlabour-risks-in-the-minerals-supply-chain.htm 